\title{
ANALES DE \\ ANTROPOLOGÍA
}

\author{
Volumen 52-II
}

Julio-diciembre 2018

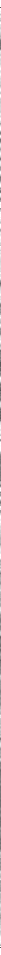

ISSN 0185-1225 


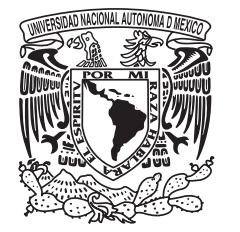

\section{ANALES DE ANTROPOLOGÍA}

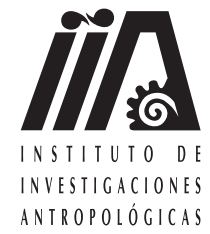

Anales de Antropología 52-2 (2018): 5-6

www.revistas.unam.mx/index.php/antropologia

\section{Editorial}

Este segundo volumen del año también es misceláneo y refleja tanto la amplia variedad de temas antropológicos como la madurez metodológica alcanzada en la profesión, evidente en el uso de estrategias de estudio probadas para aportar información sobre nuevos grupos o áreas. Inicia con dos artículos de antropología física que, conforme a la tendencia cada vez mas acentuada de esta área de conocimiento, responden a estudios realizados en grupos vivos.

García y coautores proponen una metodología para estandarizar la definición del sexo en individuos subadultos (0-16 años) a partir de la osteometría del ilion, logrando una asignación correcta en un $75 \%$, resultado de interés tanto para el estudio de poblaciones prehispánicas como para la antropología forense. Por su parte, Espinoza y sus coautores estudian el perfil genético de poblaciones de Chiapas y Nicaragua de probable filiación otomangue, para evaluar la presencia más sureña de estegrupolingüísticoen América, probableresultadodemigraciones tardías en regiones ocupadas por otras familias de idiomas.

Los siguientes cuatro artículos son de arqueología y tocan temas de resiliencia ante el cambio climático, la economía, la organización política y ritual. Villalobos analiza dos momentos de cambio climático, el final del Pleistoceno con el Younger Dryas (12 800 a 11600 ap) y el Altitermal (7 500 a 4500 ap), para demostrar cómo los cambios globales afectan, a escala local, las formas de vida de los cazadores recolectores de Sonora. Sugiura y sus coautores analizan, mediante NAA y XRF, la obsidiana obtenida de contextos domésticos del Clásico tardío y Epiclásico en dos sitios del valle de Toluca. La evidencia muestra que el valle, que durante el Clásico medio formaba parte de la periferia del Estado teotihuacano, después del ocaso de la urbe emergió como un redistribuidor de la obsdiana de Ucareo. Por otro lado, Borejsza analiza críticamente las interpretaciones obtenidas de la comparación entre los datos históricos y arqueológicos en torno a las capitales de los matlatzincas en el valle de Toluca en los siglos Xv y xvI, y el efecto de las conquistas tenochca y española en su organización.

Taladoire, en un abordaje original, compara la presencia del conejo por una parte en el registro arqueológico y por la otra en la iconografía, principalmente en el altiplano central mexicano, desde la prehisoria a la época mexica y llega a la conclusión de que a medida que el conejo va adquiriendo un valor ritual y simbólico, su consumo doméstico disminuye. Los siguientes tres artículos de antropología social usan un enfoque etnográfico para acercarse al sentido de los rituales de distintos grupos tradicionales. Villani retoma el estudio de la Danza de los Voladores (ritual inscrito desde 2009 en la lista del Patrimonio inmaterial de la humanidad por la unesco, ich. unesco.org), y propone, con base en una revisión de los datos arqueológicos, antropológicos e históricos, combinada con entrevistas a totonacas de la región de El Tajín, Veracruz, en México, que la asociación con la simbología solar fue tardía (tolteca), mientras el origen del ritual tendría más bien el sentido de intervenir contra las fuerzas destructivas del huracán.

Los siguientes dos artículos de antropología social se integran en el formato del registro etnográfico clásico, con observación participante, para acercarse al significado profundo de ciertas prácticas rituales familiares y comunidatarias. España estudia cómo un ritual, el "poner la flor", se practica habitualmente para pedir y agraceder abundancia y salud entre los otomíes del estado de Hidalgo en México, sin que ellos mismos conozcan el mito que le dio origen; éste sólo es transmitido a escasos miembros de la comunidad. Por su parte, Branca estudia, en una familia aymara de Puno, Perú, los rituales de luto realizados durante los días de muertos que se extienden durante tres años después del fallecimiento de un miembro, para lograr debidamente el "despacho del alma" del difunto. 
Los siguientes dos artículos abordan el tema de los conflictos derivados del desalojo de tierras y reclamos territoriales. Vigil hace un resumen histórico del proceso de ocupación y explotación de la selva amazónica peruana, desde las misiones hasta los conflictos armados en nuestros días, lo cual tuvo como resultado el desplazamiento, la discriminación y hasta el exterminio de los grupos ashaninkas que ocupaban originalmente ese territorio. En un plan más estadístico, Palomeque y sus coautores analizan mediante encuestas, el grado de conformidad de la población después de la aplicación de un programa de redefinición de límites territoriales de cinco cantones colindantes de la provincia del Canar, en Ecuador. Este programa, que procuró encontrar soluciones pacíficas a los procesos de deslinde territorial, fue relizado por el Centro de Mediación de la misma Universidad Católica de Cuenca.

El volumen cierra con las reseñas de dos libros editados en 2016 y una sobre un libro de 2015: la primera, de la pluma de Pitarch, aborda un libro bilingüe accesible en línea, con narraciones de hombres y mujeres tzotziles. El segundo libro, revisado por Oehmichen, es el trabajo editado por varios autores latinoamericanos, Patrimonio y pueblos indigenas. Neyra Alvarado traduce la reseña realizada por Leonardo Piasere al libro de Williams. 